\title{
Special issue: 30th International Conference on Flexible Automation and Intelligent Manufacturing (FAIM2021)
}

Published online: 3 June 2021

(C) Springer-Verlag London Ltd., part of Springer Nature 2021

The following articles are part of the Special Issue "30th International Conference on Flexible Automation and Intelligent Manufacturing (FAIM2021)" Guest Edited by George-C. Vosniakos, Marcello Pellicciari, Panorios Benardos, Angelos Markopoulos and were inadvertently published in a different issue:

"Effect of datum system and datum hierarchy on the design of functional components produced by additive manufacturing: a systematic review and analysis" Christos Vakouftsis, Andreas Mavridis-Tourgelis, Georgios Kaisarlis, Christopher G. Provatidis and Vasilios Spitas (2020). The International Journal of Advanced Manufacturing Technology 111(34):817-828. https://doi.org/10.1007/s00170-020-06152-6

"An integrated homogenization-based topology optimization via RBF mapping strategies for additively manufactured FGLS and its application to bandgap structures" Ugur Simsek, Cemal Efe Gayir, Gullu Kiziltas and Polat Sendur (2020). The International Journal of Advanced Manufacturing Technology 111(5-6):1361-1374. https://doi.org/10.1007/s00170-020-06207-8

"Computational implementation of part stiffness on tolerance specification based on the functional performance of assemblies" Andreas Mavridis-Tourgelis, Christos Vakouftsis, Georgios Kaisarlis, Vaios G. Arampatzis, Christopher G. Provatidis and Vasilios Spitas (2020). The International Journal of Advanced Manufacturing Technology 111(1-2):397-410. https://doi.org/10. 1007/s00170-020-06139-3

"Porous collagen scaffold micro-fabrication: feature-based process planning for Computer Numerically Controlled laser systems" Stylianos Kechagias, Fereniki Moschogiannaki, Emmanuel Stratakis, Dimitrios S. Tzeranis and George-Christopher Vosniakos (2020). The International Journal of Advanced Manufacturing Technology 111(3-4):749-763. https://doi.org/10. 1007/s00170-020-06131-x

"Enhancement of accuracy in double sided incremental forming by compensating tool path for machine tool errors" P. Konka, R.
Lingam, U. A. Singh, CH. Shivaprasad and N. V. Reddy (2020). The International Journal of Advanced Manufacturing Technology 111(3-4):1187-1199. https://doi.org/10.1007/ s00170-020-06149-1

"On the integration of FBG sensing technology into robotic grippers" Paolo Tripicchio, Salvatore D'Avella, Carlo Alberto Avizzano, Fabrizio Di Pasquale and Philippe Velha (2020). The International Journal of Advanced Manufacturing Technology 111(3-4):1173-1185. 10.1007/s00170-020-06142-8

"Welding defect detection: coping with artifacts in the production line" Paolo Tripicchio, Gerardo Camacho-Gonzalez and Salvatore D'Avella (2020). The International Journal of Advanced Manufacturing Technology 111(5-6):1659-1669. https://doi.org/10.1007/s00170-020-06146-4

"An integrated system for automated 3D visualization and monitoring of vehicles" Stella Bounareli, Ioannis Kleitsiotis, Lampros Leontaris, Nikolaos Dimitriou, Aggeliki Pilalitou, Nikolaos Valmantonis, Efthymios Pachos, Konstantinos Votis and Dimitrios Tzovaras (2020). The International Journal of Advanced Manufacturing Technology 111(56):1797-1809. https://doi.org/10.1007/s00170-020-06148-2

"Complex scheduling network: an objective performance testing platform for evaluating vital nodes identification algorithms" Zilong Zhuang, Yu Chen, Yanning Sun and Wei Qin (2020). The International Journal of Advanced Manufacturing Technology 111(1-2):273-282. https://doi. org/10.1007/s00170-020-06145-5

"An intelligent framework for modelling and simulation of artificial neural networks (ANNs) based on augmented reality" D. Mourtzis and J. Angelopoulos (2020). The International Journal of Advanced Manufacturing Technology 111(5-6):1603-1616. https://doi.org/10.1007/s00170-020-06192-y

Publisher's note Springer Nature remains neutral with regard to jurisdictional claims in published maps and institutional affiliations. 